\title{
Application of Bio-Modified Montmorillonite Clay to Enhance Asphalt Oxidation Resistance
}

\author{
${ }^{1}$ Shahrzad Hosseinnezhad, ${ }^{2}$ Elham H. Fini and ${ }^{2}$ Taher M. Abu-Lebdeh \\ ${ }^{I}$ Department of Research and Economy Development, \\ North Carolina A\&T State University, 1601 E. Market St., Greensboro, NC, 27411, USA \\ ${ }^{2}$ Department of Civil, Architectural and Environmental Engineering, \\ North Carolina A\&T State University, Greensboro, NC 27411, USA
}

\author{
Article history \\ Received: 17-02-2018 \\ Revised: 28-02-2018 \\ Accepted: 31-03-2018 \\ Corresponding Author: \\ Taher Taher M. Abu-Lebdeh \\ Department of Civil, \\ Architectural and \\ Environmental Engineering, \\ North Carolina A\&T State \\ University, Greensboro, NC \\ 27411, USA \\ Email: taher@ncat.edu
}

\begin{abstract}
This study evaluates the effectiveness of using a Bio-modified Nanoclay additive (BNC) to reduce the oxidative aging of asphalt pavements. The study results through X-Ray Diffraction analysis showed that the modification of montmorillonite clay with bio-modifier increased the basal d-spacing of clay. The resulting nanoclay with increased interlayer spacing was chosen for application in asphalt binder. Rheological characterization of clay-modified asphalt binder were studied before and after oxidation aging. The effects of BNC on asphalt complex modulus were observed to be prevailing in the intermediate to high-temperature range. The aging resistance of asphalt binder showed improvement with the addition of nanoclay and the improvement was more notable in presence of bio modified-nanoclay than pure clay.
\end{abstract}

Keywords: Asphalt Oxidation, Clay, Bio-Modified Asphalt, Bio-bonder, Aging Resistance

\section{Introduction}

Pavement materials are exposed to various environmental conditions, which can lead to pavement deterioration such as repeated loading, thermal stress, chemical deterioration and oxidative aging. This has led to extensive research efforts to design and maintain pavement for extended service life. According to the National Asphalt Pavement Association, 7\% of the Gross Domestic Product is allocated for maintenance of transportation infrastructure (You et al., 2011).

Chemical and physical characteristics of asphalt are altered due to exposure to heat, oxygen and ultraviolet light, causing the asphalt to "age" (El-Shafie et al., 2012). Oxidation influences the aging effect in asphalt samples as it causes pavement degradation and consequent moisture damage to binder, which leads to embrittlement and distress, such as cracking (Yao et al., $2013 ; 2015)$. Modifiers have been used mainly to extend asphalt's high- and low-temperature performance grade or to enhance the aging resistance of asphalt binder.

In addition, environmental concerns of the asphalt industry have led to the promotion of green asphalt technologies (Rubio et al., 2012). Research on sustainable alternatives for asphalt binder has led to the application of bio-based asphalt binder to be used as a modifier or alternative for bituminous asphalt (Fini et al., 2012). Bio-binder is produced from non-petroleumbased renewable resources like wood, corn and animal waste (Hosseinnezhad et al., 2015). Recent research efforts have suggested using a bio-binder along with petroleum-based asphalt to produce a bio-modified binder with enhanced performance (Fini et al., 2012; 2010; Williams et al., 2015).

Nano-particles have commonly been used in the polymer industry to achieve increased mechanical and physical properties such as stiffness, toughness, strength and thermal stability (Lee et al., 2005). The use of nanoparticles as modifiers in asphalt binders may help address various performance-related problems of asphaltic pavement (You et al., 2011; Goh et al., 2011; Amirkhanian et al., 2010). Jahromi et al. studied the effects of the addition of Cloisite 15A nanoclay as a modifier in asphalt mixtures. Cloisite $15 \mathrm{~A}$ is a natural montmorillonite polymer additive that has already been modified with ammonium salt. A binder modified with this nanoclay was shown to have enhanced resistance to aging and rutting effects. Unfortunately, fatigue- 
cracking performance was decreased at low temperatures. While stability was increased by $6 \%$ $15 \%$, high temperatures were also shown to increase tensile strength by as much as $40 \%$ (Jahromi and Khodaii, 2009). Furthermore, the addition of nanoclay decreased the asphalt mixture's susceptibility to moisture damage (You et al., 2011; Goh et al., 2011).

This study focuses on the production of a bio-modified nanoclay to enhance a binder's rheological properties. It is hypothesized that nano-particles will be exfoliated by introduction of bio-binder into the layer of nanoclay, producing a well-stabilized bio-modified nanoclay while improving the high-temperature properties and aging characteristics of the modified binder.

Montmorillonite (MMT) is a natural mineral that consists of layers with thickness of one nm. Since there are strong electrostatic forces between the layers, unmodified clays cannot disperse well in organic matrices. However, when the interlayer sodium ions between the interlayer are replaced with suitable organic cations, the surface acquires an organic character. This leads to increased interlayer spacing and exfoliation of the platelet sheet, which can be facilitated as the binder matrix intercalates between the layers. Common choices for the organic surfactants are ammonium ions substituted with one or more aliphatic chains of 12 or more carbons (Zulfiqar et al., 2008; Yariv and Cross, 2002).

The dispersion of clay particles in the matrix binder can form intercalated structure with the introduction of binder between the layers, but the layers remain parallel. In the exfoliated structure: The layered structure of the clay is disordered, the silicate layers are no longer close enough to interact with each other (Ramos Filho et al., 2005; Gupta et al., 2005; Garcia-Lopez et al., 2005).

Bio-binder, which is used in this study, is an amideenriched organo-modifier produced from swine manure. Previous studies showed that amide derivatives are among the main components of the bio-products extracted from certain bio-mass, including swine manure (Du et al., 2011). Hexadecanamide (palmitic amide), N(3-Methylbutyl) and N-(2-phenylethyl) acetamide are examples of the amide-type components that exist in biobinder and bio-crude samples (Mousavi et al., 2016a).

In the present study a mechanism was suggested by using hexadecanamide (palmitic amide) as a representative of amide molecule to interact with clays molecules. A suggested mechanism involves hydrogen bonds between the nitrogen of the amide chain and oxygen of the silicate layers of clay. Another mechanism suggested previously involves interactions between hydrophobic siloxanes $(\mathrm{Si}-\mathrm{O}-\mathrm{Si})$ and $(\mathrm{CH} 2)_{\mathrm{n}}$ segments along an amide backbone (Touchaleaume et al., 2011). According to these, the bio-binder was used in the study was assumed to exfoliate and intercalate the silicate layers of nanoclay. Then this modified organoclay was used for modification of asphalt binder to increase its aging resistance.

\section{Materials}

The asphalt binder was chosen in this study was asphalt binder PG 64-22. The nanoclay is Nanofil 116, a natural montmorillonite (MMT-Na) with a Cationic Exchange Capacity (CEC) of $116 \mathrm{mEq} / 100 \mathrm{~g}$ clay, supplied from Southern Clay Products. The bio-binder, derived from swine manure, was produced at North Carolina A\&T State University. The bio-binder was processed via a thermochemical liquefaction process (at working pressure of 4.5 $\mathrm{MPa}$ and temperature of $360^{\circ} \mathrm{C}$ ) followed by filtration and post-processing (Fini et al., 2010).

\section{Fabrication of Bio-Modifed Nanoclay (BNC)}

Nanoclay in three ratios of $1: 4,1: 2$ and $3: 4$ of the weight of bio-binder were chosen and called MMT/BB (75), MMT/BB (50), MMT/BB (25) respectively. Nanoclay was pre-swelled in acetone and deionized water at $50^{\circ} \mathrm{C}$ for $15 \mathrm{~min}$ while it was mixed on the hot plate. Then, it was left at room temperature for $24 \mathrm{~h}$ for additional swelling time. After that, the bio-binder was mixed with acetone in a separate container and the two mixtures were blended with a high-shear mixer for 15 $\mathrm{min}$ at $3500 \mathrm{rpm}$. Ultrasound was conducted for $10 \mathrm{~min}$, followed by centrifuge for $30 \mathrm{~min}$ at $1500 \mathrm{rpm}$. After removing solvents, the precipitant, which was called Bio-Modified Nanoclay (BNC), was dried overnight.

\section{Fabrication of Bio-Modified Nanoclay Asphalt}

The modified asphalt materials were prepared using a high-shear mixer. The bitumen was first heated at about $135^{\circ} \mathrm{C}$ until it became fluid in the mixer. After that, $2 \%$ of modifiers (by weight of base binder) was added to the asphalt binder when it reached $135^{\circ} \mathrm{C}$ and the mixture was blended at $2500 \mathrm{rpm}$ for $3 \mathrm{~h}$. Two types of binders were prepared: Unmodified-nanoclay (NC) binder and Bio-modified Nanoclay (BNC) binder.

\section{Testing Methods}

In order to study the effect of nanoclay on the aging resistance of asphalt binder, the modified and neat binders were aged initially using the Rolling Thin-Film Oven (RTFO) followed by $20 \mathrm{~h}$ aging in the Pressure Aging Vessel (PAV).

\section{Rotational Viscometer Test (RV)}

Viscosity measurements were conducted using a Brook eld Viscometer RV-DVIII Ultra, following ASTM D4402. Age hardening can be quantified in terms of viscosity measurement by the use of an aging index, which can be defined as equation 1; high values of the ratio indicate a high degree of asphalt hardening 
(Zhang et al., 2012). The Viscosity Aging Index (VAI) is used to evaluate the aging extent and is calculated using the viscosity of the samples before and after short-term (RTFO) aging or before and after exposure to Pressure Aging Vessel (PAV) aging, which is designed to simulate in-service oxidative aging of asphalt binder:

$$
V A I=\frac{\text { Aged viscosity value }- \text { Unaged viscosity value }}{\text { Unaged viscosity value }}
$$

\section{Dynamic Shear Rheometer (DSR)}

The complex modulus $\left(\mathrm{G}^{*}\right)$ is a measure of total resistance of the binder to deformation when repeatedly sheared and the phase angle $(\delta)$ is the lag between the applied shear stress and the resulting shear strain. Traditionally, $\mathrm{G}^{*} / \sin \delta$ is used to evaluate asphalt binder rutting resistance at high pavement temperatures. The asphalt binder with the higher $\mathrm{G}^{*} / \sin \delta$ suggests a higher resistance to permanent deformation or rutting of asphalt pavement.

In order to determine aging susceptibility for modified asphalts, the DSR was utilized to characterize both aged and unaged materials in accordance with ASTM D7175using a Malvern Kinexus DSR.

The data were collected at $64^{\circ} \mathrm{C}$ and $10 \mathrm{rad} / \mathrm{s}$. The resulting data were then used to determine the Rheological Aging Index (RAI) of each specimen using Equation 2 (Fini et al., 2017):

$$
R A I=\frac{\frac{G_{\text {Aged }}^{*}}{\sin \delta \text { aged }}}{\frac{G_{\text {Unaged }}^{*}}{\sin \text { Sunaged }}}
$$

The MSCR test was also performed on the samples following ASTM D7405. The MSCR test is used to determine the rutting susceptibility of the asphalt binder (Jnr) and \% Recovery, which is related to the binder's elastic and viscous properties. Both modified and unmodified specimens were tested at $64^{\circ} \mathrm{C}$ for stress levels of $0.1 \mathrm{kPa}$ and $3.2 \mathrm{kPa}$.

\section{Bending Beam Rheometer (BBR)}

According to the Superpave ${ }^{\mathrm{TM}}$ specification, the low-temperature performance of nano clay modified asphalt binders are evaluated using the Bending Beam Rheometer (BBR) test. The test evaluates the binder's ability for stress relaxation to prevent thermal cracking caused by a sudden drop of temperature in the cold season. In this study, the testing temperature was selected to be $-12^{\circ} \mathrm{C}$. The test is conducted through a three point bending test while measuring the deformation at the mid span of the beam under a constant load; collected deformation data during the loading time are then used to calculate stiffness using Equation 3 (Yang et al., 2013):

$$
S(t)=\frac{P L^{3}}{4 b h^{3} \delta(t)}
$$

\section{Where:}

$P=$ Applied constant load $(100 \mathrm{~g}$ or $0.98 \mathrm{~N})$

$L=$ Distance between beam supports $(102 \mathrm{~mm})$

$b=$ Beam width $(12.5 \mathrm{~mm})$

$h=$ Beam thickness $(6.25 \mathrm{~mm})$

$S(t)=$ Asphalt binder stiffness at a specific time

$\delta(t)=$ Deflection at a specific time

\section{Attenuated Total Reflectance Fourier Transform Infrared Spectroscopy (ATR-FTIR)}

The Thermo Scientific Nicolet iS10 FT-IR Spectrometer was used in was used in Absorbance mode to acquire the spectra of each sample. Wave numbers ranging from 4000 to $600 \mathrm{~cm}^{-1}$ were covered. The background spectrum was taken after cleaning the prism with methylene chloride. For ATR-FTIR, the spectra are obtained by placing a thin layer of bitumen on the surface of internal reflection element. In this method, a non-absorbing prism is used for total internal reflectance of infrared light. Contact of absorbing substances with the prism surface will attenuate the internally reflected light and provides an infrared absorption spectra (Karllsson et al., 2006).

\section{XRD Test}

X-ray diffraction (XRD) graphs were obtained using Dual wavelength system $\mathrm{Cu}$ Ka radiation $\left(1^{1} \frac{1}{4} 0.154 \mathrm{~nm}, 40\right.$ $\mathrm{kV}, 120 \mathrm{~mA}$ ) at room temperature. This method has been the principal method for determining the arrangement of atoms in minerals and metals.

In this study, XRD technique quantitatively measures the interlayer spacing of bio-modified nanoclay. Decrease or increase in the interlayer spacing (d-spacing) determines the degree of intercalation of nanoclay layers. The interlayer spacing of the MMT can be calculated according to the Bragg equation:

$n \lambda=2 d \sin \theta$

where, $\lambda$ is wavelength of the rays, $\theta$ is the angle between the incident rays and the surface of the crystal and $d$ is the spacing between the layers of atom and $n$ is any integer. $n$ was considered 1 in the calculation.

\section{Results and Discussion}

The effects of two types of modifiers nanoclay (NC and $\mathrm{BNC}$ ) on asphalt viscosity were studied. Figure 1 
shows the viscosity aging index after samples being exposed to PAV aging. The viscosity aging index results showed that aging was decreased after modifying with $\mathrm{NC}$ and $\mathrm{BNC}$. Better resistance to aging was for $\mathrm{BNC}$ compared to NC. This improvement of aging resistance after bio-modification is due to the better dispersion of the silicate platelet nanoclay particles inside the binder that hinder the movement of bitumen, because of the presence of intercalated particles or even the exfoliated structure reduction is $18 \%$ for $\mathrm{NC}$ and $35 \%$ for $\mathrm{BNC}$.

\section{FTIR Analysis}

The FTIR spectra of NC is shown in Fig. 2, along with the spectra of BNC with different ratios of biobinder. Two peaks at 3620 and $3428 \mathrm{~cm}^{-1}$ are attributed to the stretching of $-\mathrm{OH}$, which is the result of the presence of water in nanoclay montmorillonite. The peak at $1030 \mathrm{~cm}^{-1}$ is resulted from the stretching vibrations of $\mathrm{Si}-\mathrm{O}$ and the peaks at 520 and $470 \mathrm{~cm}^{-1}$ are resulted from the bending absorptions of $\mathrm{Si}-\mathrm{O}$ and $\mathrm{Al}-\mathrm{O}$ bonds in the MMT structure (Hrachova et al., 2007; Su et al., 2008). In the spectra of MMT/BB (5) and MMT/BB (25), new peaks appeared at 2925 and $2851 \mathrm{~cm}^{-1}$. These peaks are caused by $\mathrm{C}-\mathrm{H}(-\mathrm{CH} 2,-\mathrm{CH} 3)$ stretching and bending absorptions in the organic intercalation agent (Zhang et al., 2011). The intensity and sharpness of these peaks are higher for MMT/BB (50) which is an indication of better intercalation of bio-binder's molecules in this ratio. The related peaks were not observed for MMT/BB (75) which could result from a higher percentage of bio-binder and the consequent surface saturation of the nanoclay structure with biobinder molecules instead of having enough available silicate sites for interaction with bio-binder's amide molecules. The peak at $1636 \mathrm{~cm}^{-1}$ resulted from bending vibration of an $\mathrm{O}-\mathrm{H}$ group and broadening and reduction in the intensity of this peak is another example of the intercalation of bio-binder molecules (Su et al., 2008).

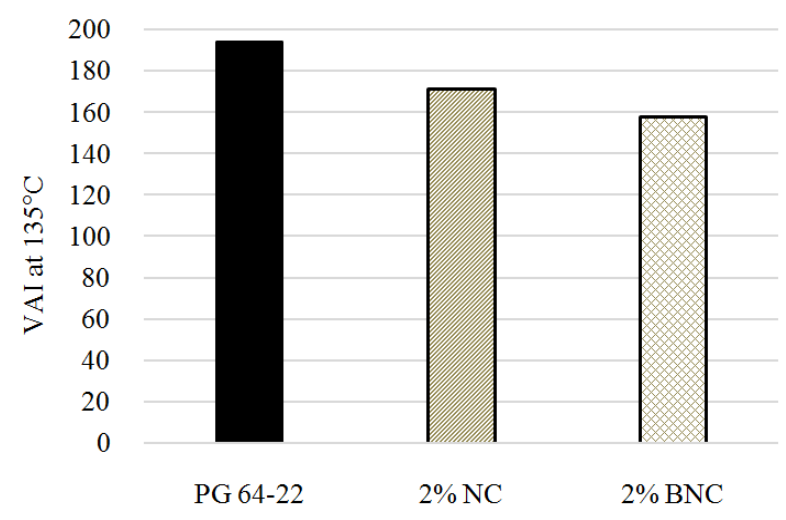

Fig. 1: Viscosity Aging Index results of PAV aging for PG 64$22,2 \% \mathrm{NC}$ and $2 \% \mathrm{BNC}$ modified binders at $135^{\circ} \mathrm{C}$

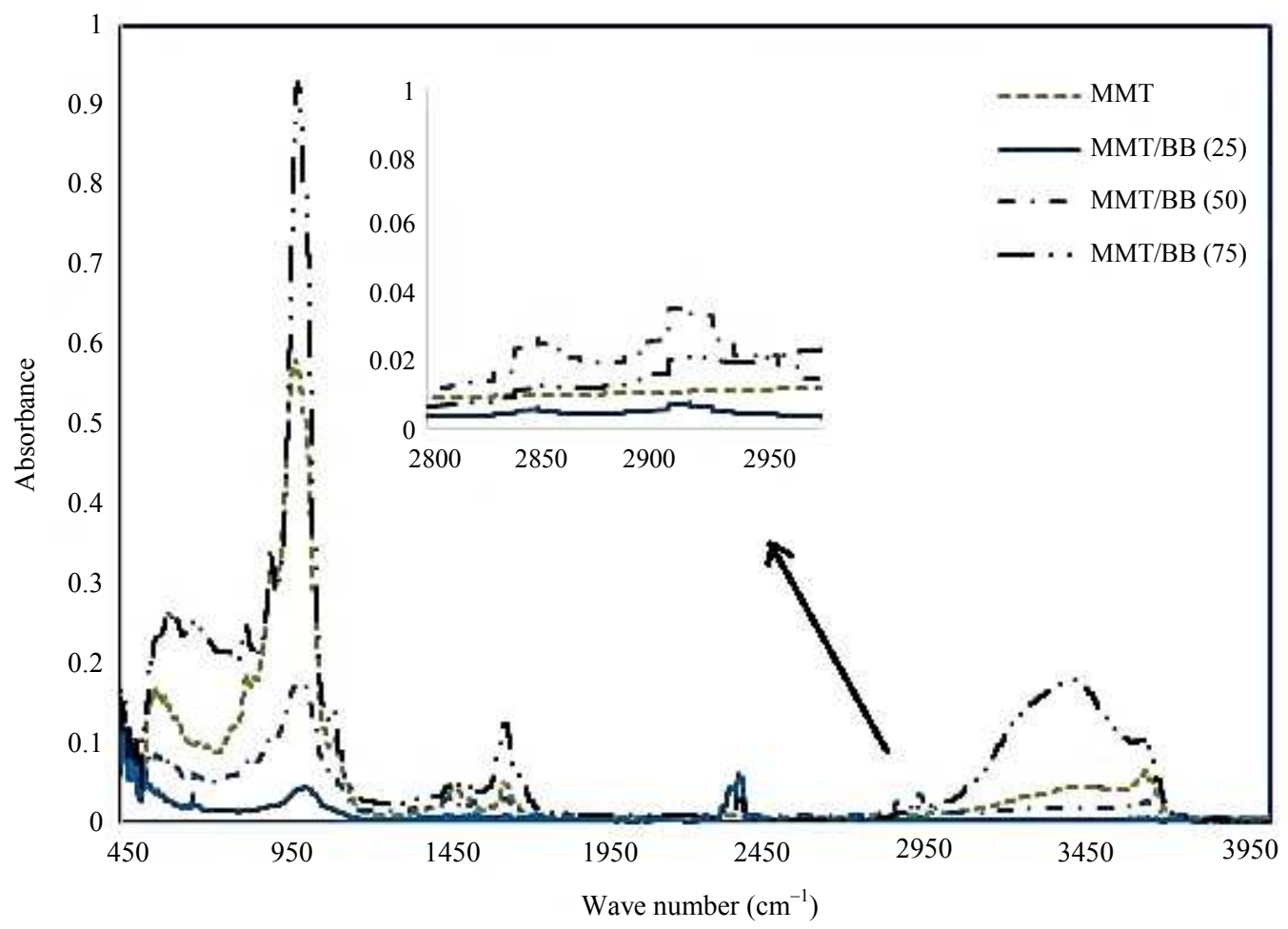

Fig. 2: FTIR spectra of MMT and modified MMT with three different ratios of MMT/BB 
This peak was reduced and broadened for MMT/BB (50), but for MMT/BB (75), it was still sharp; this shows that MMT/BB (50) has better intercalated structure. In the spectra of MMT/BB (25), that peak disappeared; also peaks related to 2925 and $2851 \mathrm{~cm}^{-1}$ that are an indicator of the presence of organic molecules of $\mathrm{BB}$ in the layer of MMT are missing for this ratio of MMT/BB (25). Therefore, MMT/BB (50) seems to have a better intercalated or even exfoliated structure than the two other ratios of MMT/BB. Thus, MMT/BB (50) was chosen for modification of asphalt binder, based on this result in combination with the result of XRD analysis.

\section{XRD Analysis}

X Ray Diffraction (XRD) analysis was used to study the interlayer spacing of nanoclay, which shows the degree of intercalation or exfoliation of the clay particles. This interlayer has been calculated by the XRD patterns of Montmorillonite (MMT) and modified MMT with bio-Binder (BB) with the ratios of MMT/BB (75), MMT/BB (50) and MMT/BB (25) the results of the calculations are given in Table 1 . The interlayer spacing of clay (d001) due to the modification of clay with amideenriched molecules, increased from $1.23 \mathrm{~nm}$ for MMT to $1.43 \mathrm{~nm}$ for MMT/BB (50). This increase shows the intercalation of the clay gallery space; therefore, the MMT/BB (50) may form an intercalated or exfoliated structure. The MMT/BB (50), had the largest interlayer spacing compared to the other two versions. The second largest spacing is achieved in the MMT/BB (25), then the
MMT/BB (75). Therefore, MMT/BB (50) was chosen as the modifier for investigating the effect of bio-modified nanoclay on asphalt oxidative aging resistance.

Like other bio-derivatives, bio-binder consists of different molecules, since it is derived from bio-oil. Amide compounds are the predominant compound in bio-binder. Due to the very active functional group of amide, the amide compounds can even act as an independent additive (Mousavi et al., 2016b). Hexadecanamide is one of the amide components in the bio-binder structure. The introduction of bio-binder to the pre-swelled MMT promotes hydrogen bonding between the silicates layer of the nanoclay and the nitrogen of the amide (Maiti and Okamoto, 2003). The result of this interaction is intercalating of the silicate layers. Figure 3 shows the possible mechanism between a silica layer and truncated schematic of hexadecanamide. Hydrogen bonds between the amide and oxygen of the silicate surface, provide better adhesion of bio-binder to nanoclay (Liu et al., 2010). This interaction enhances the compatibility of modified nanoclay with the organic nature of the asphalt matrix.

Table 1: d-Spacing Based on XRD Results for MMT and BioModified MMT

\begin{tabular}{lll}
\hline Sample name & 2 theta & d-spacing $(\mathrm{nm})$ \\
\hline MMT & 7.2 & 1.23 \\
MMT/BB (50) & 6.16 & 1.43 \\
MMT/BB (75) & 6.90 & 1.27 \\
MMT/BB (25) & 6.42 & 1.37 \\
\hline
\end{tabular}

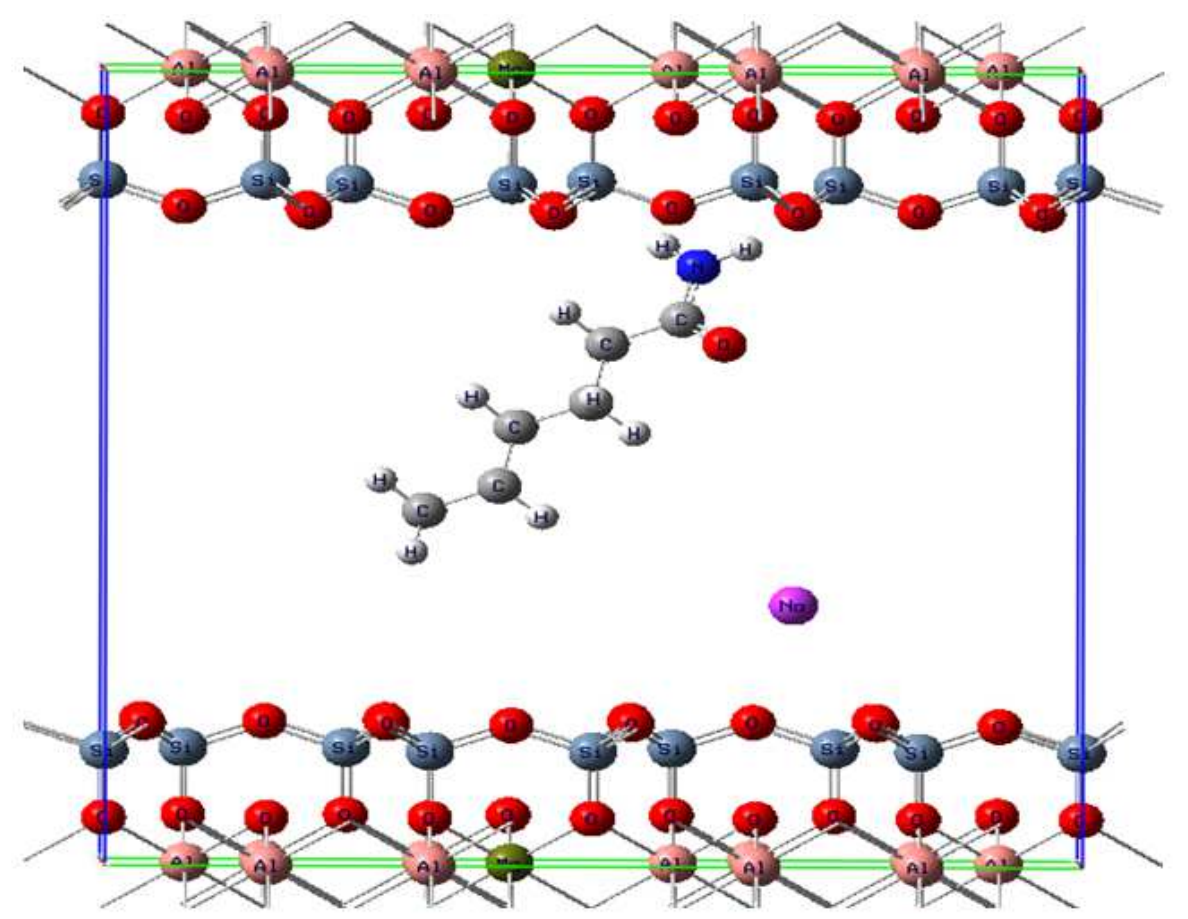

Fig. 3: Possible Mechanism between Hexadecanamide and MMT layer 
The aging resistivity potential of modified asphalt binders was evaluated by estimating the rheological aging index (RAI) by using equation 2 and shown in Fig. 4, based on the result of complex modulus and phase angle at two frequencies, $10(\mathrm{rad} / \mathrm{sec})$ and $1(\mathrm{rad} / \mathrm{sec})$, measured at a temperature of $64^{\circ} \mathrm{C}$, this aging index was called RAI-1. The frequency $10 \mathrm{rad} / \mathrm{sec}$ is a standard angular frequency recommended by Superpave to evaluate the rutting potential of asphalt binder. A higher aging index shows higher susceptibility towards aging and vice versa. The significant change in aging resistance confirms the better distribution and exfoliation of nanoclay plates with BNC-modified binder. These nano-particles have the role of oxygen barrier during the aging process and prevent the movement of lighter components of asphalt binder to slow the aging process (Lamontagne et al., 2001).

Figure 5a shows the percent recovery values obtained from the MSCR test at $0.1 \mathrm{kPa}$. The addition of $2 \% \mathrm{BNC}$ increased the recovery value $R$ from 0.50 to $1.6 \%$ for unaged binders, indicating a better performance of BNCmodified binder in terms of rutting and fatigue. Before aging, no increment was seen for $2 \%$ NC-modified binder. A similar trend was observed for PAV-aged samples: The $R$ value increased from $19.2 \%$ for aged unmodified binder to $45.8 \%$ for aged $2 \%$ BNC-modified binder. This enhancement shows better distribution of nano-particles due to the exfoliation effect of bio-binder. So the use of amide-enriched bio-binder caused better separation of silicate layers. This separation improved the elastic recovery of asphalt binder while reducing aging susceptibility.

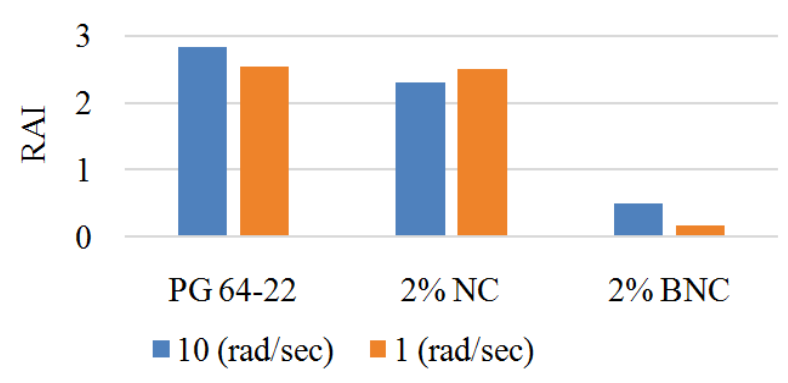

Fig. 4: Rheological Aging Index (RAI) at frequency of 10 $\mathrm{rad} / \mathrm{sec}$ and $1 \mathrm{rad} / \mathrm{sec}$ at $64^{\circ} \mathrm{C}$

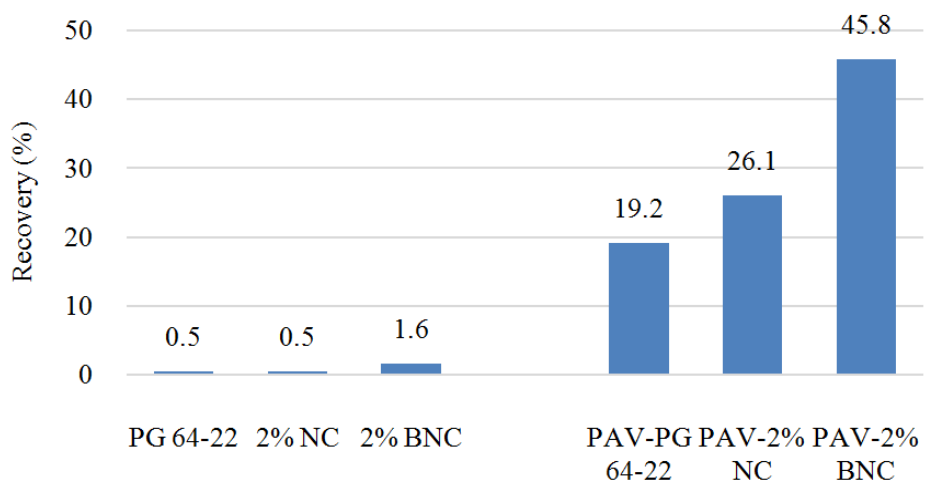

(a)

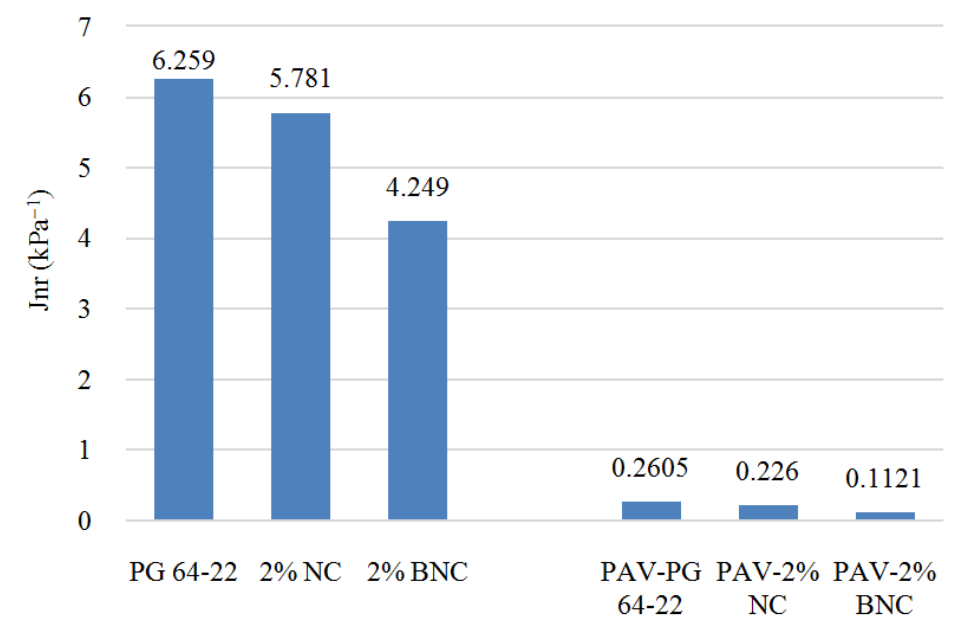

(b)

Fig. 5: (a) Elastic recovery result for unaged and PAV-aged asphalt binders at $0.1 \mathrm{kPa}$; (b) $J_{n r}$ result for unaged and PAV-aged asphalt binders at $0.1 \mathrm{kPa}$ 


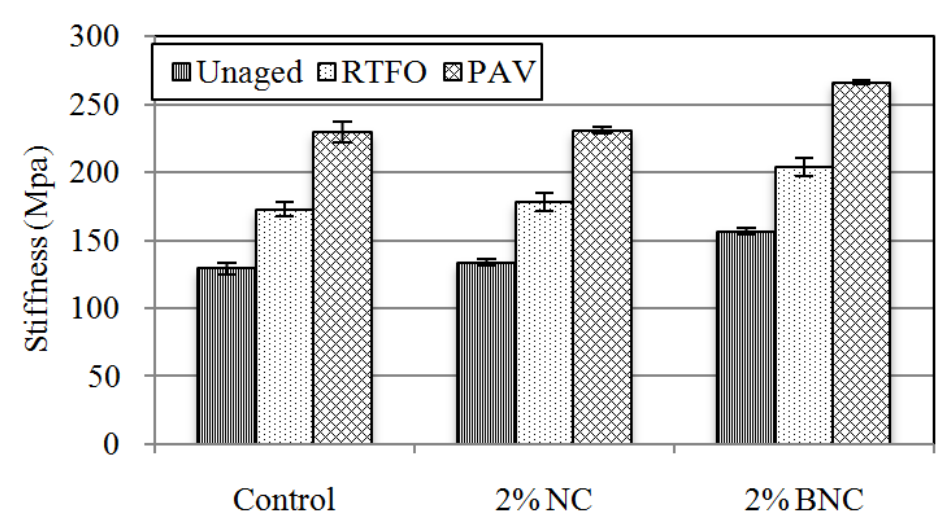

(a)

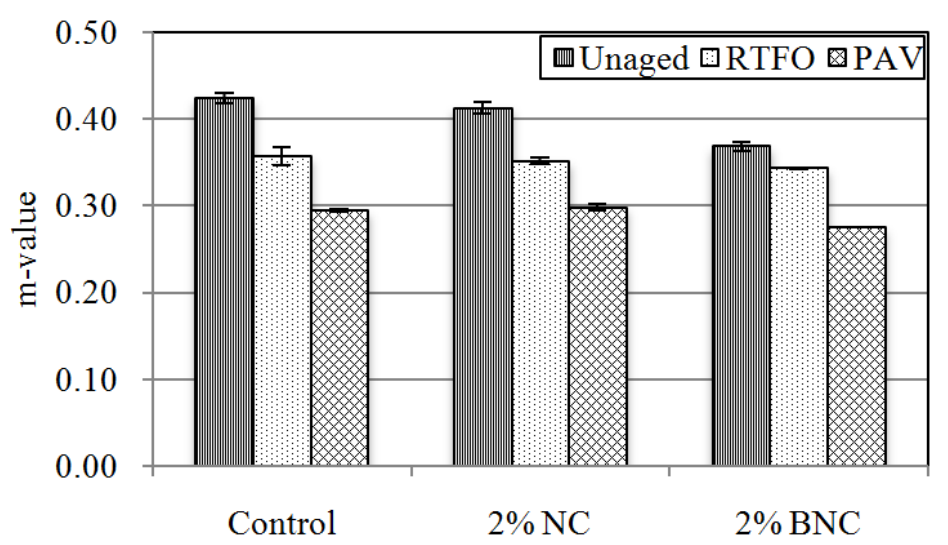

(b)

Fig. 6:(a) Stiffness Values for Control, $2 \% \mathrm{NC}$ and $2 \% \mathrm{BNC}$ for Unaged, RTFO and PAV at $-12^{\circ} \mathrm{C}$; (b) m-values for Control, $2 \%$ $\mathrm{NC}$ and $2 \% \mathrm{BNC}$ for Unaged, RTFO and PAV at $-12{ }^{\circ} \mathrm{C}$

Figure $5 \mathrm{~b}$ shows the plot of $J$ nr values obtained from the MSCR test. The addition of BNC decreases the $J \mathrm{nr}$ value of asphalt binder. At $0.1 \mathrm{kPa}$, the $J_{n r}$ value for unmodified binder, 2\% NC-modified and 2\% BNCmodified showed as 6.259, 5.781 and 4.249, respectively. The addition of $\mathrm{BNC}$ resulted in a significant decrease in $J_{n r}$ value, which can be considered as an improvement in rutting resistance. A decrease in $J \mathrm{nr}$ may be attributed to intercalation and exfoliation of BNC-modified asphalt, which leads to an increase in stiffness value of the binder and hence improved rutting resistance. This reduction is also notable after long-term aging and the results confirm the effect of bio-modified nanoclay in increasing the aging resistance of asphalt binder.

In table 6, PAV BBR stiffness and m-values results for the control, $2 \% \mathrm{NC}$ and $2 \% \mathrm{BNC}$ are given at $-12{ }^{\circ} \mathrm{C}$. It was shown that at $2 \% \mathrm{NC}$, there is a slight $(3.5 \%)$ increase in the stiffness and decrease $(2.6 \%)$ in m-value in comparison to the unmodified binder. Modification of asphalt binder with $2 \% \mathrm{BNC}$ led to further increase in the stiffness and a decrease in m-value by 21 and $13 \%$ respectively. The same trend was observed for the RTFO and PAV specimens with 2\% BNC stiffness being $18 \%$ and $16 \%$ higher than the control binder and the m-value being $4 \%$ and $6 \%$ lower. These results showed that the modification of asphalt binder with nanoclay was not successful in low temperature performance.

The extent of change in stiffness and $m$-value before and after aging was used as another indicator of susceptibility to aging which was shown with rheological aging index 2 (RAI-2) (Fig. 7). The presence of nanoclay showed a significant impact on alleviating the effect of aging both after short and long-term aging. In presence of $\mathrm{BNC}$, both aging indices calculated based on the change in the stiffness and m-values found to be lower compared to the control binder.

\section{Aging Behavior of Modified Binders by FTIR Analysis}

The carbonyl bonding, termed as the carbonyl indices, was postulated to represent the degree of oxidation or aging within organic compounds. Understanding the carbonyl behavior within the asphalt binder and modifiers is critical in linking the 
morphological and mechanical properties of the samples. The peak at $1,700 \mathrm{~cm}^{-1}$ was due to the stretch absorption of the carbonyl group. From the FTIR spectra obtained for the control, 2\% NCmodified and $2 \%$ BNC-modified samples, the carbonyl indices were determined according to
Equation 5, using the area of the carbonyl band centered around $1700 \mathrm{~cm}^{-1}$ :

$$
I_{C=O}=\frac{\text { Area of carbonyl bond around } 1700 \mathrm{~cm}^{-1}}{\text { Area of the spectral bonds between } 2000 \text { and } 600 \mathrm{~cm}^{-1}}
$$

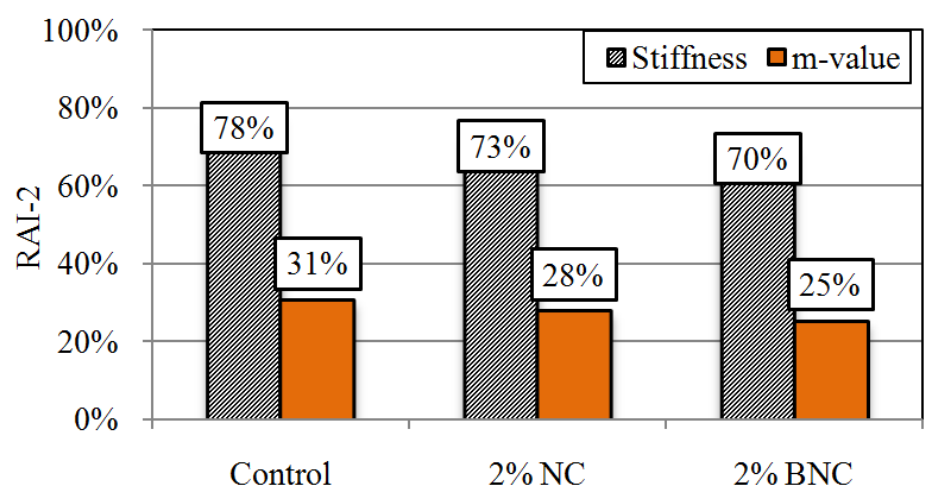

Fig. 7: $\mathrm{m}$-values for Control, $2 \% \mathrm{NC}$ and $2 \% \mathrm{BNC}$ for Unaged, RTFO and PAV at $-12{ }^{\circ} \mathrm{C}$

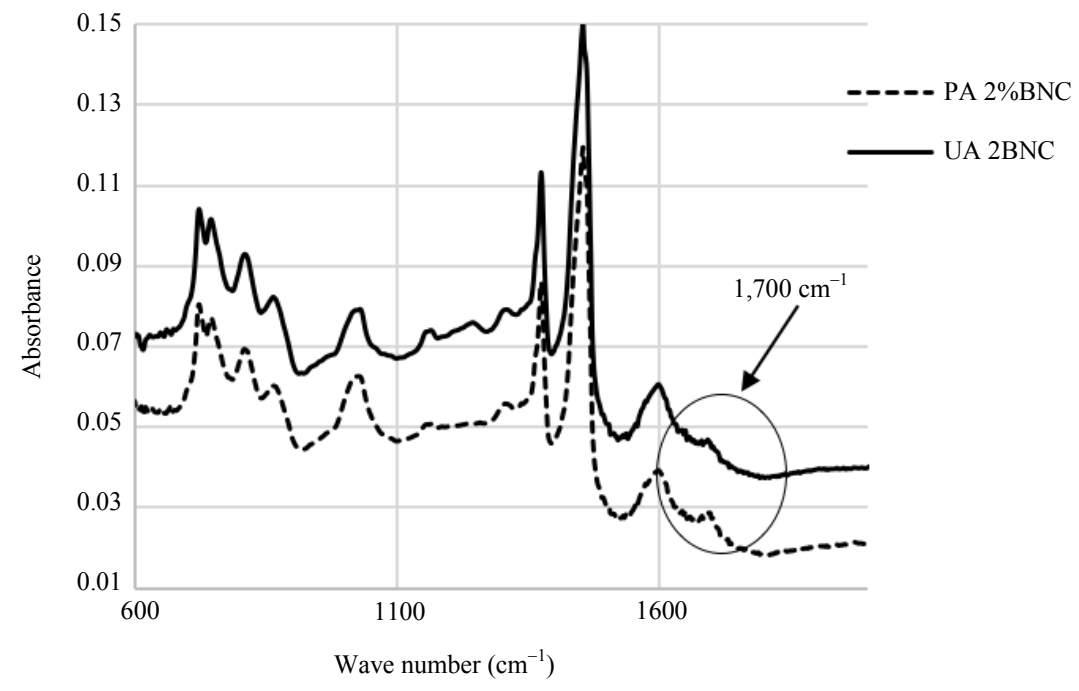

Fig. 8: FTIR Spectra for $2 \%$ BNC before (UA) and after (PA) PAV aging

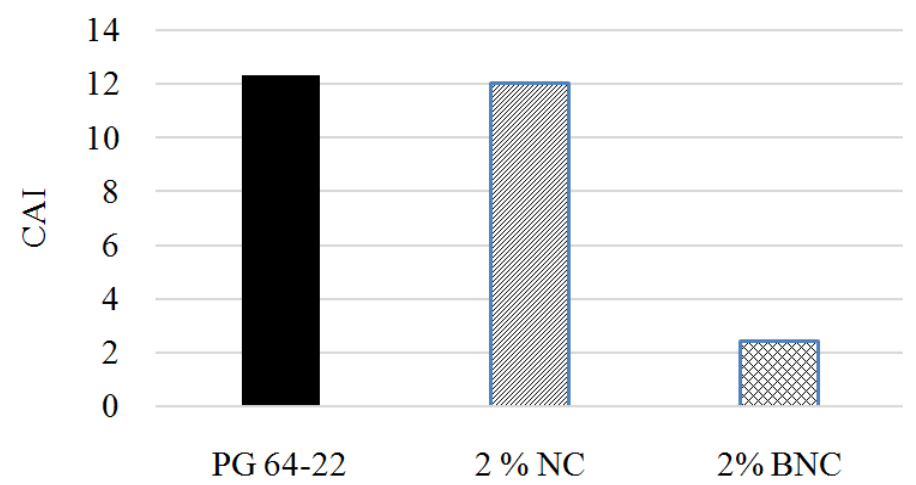

Fig. 9: Chemical Aging Index (CAI) for unmodified and modified binders 
Figure 8 shows FTIR spectra for BNC modified binder before and after PAV aging between 600-2000 $\mathrm{cm}^{-1}$ wave number.

To evaluate the rate of aging based on the carbonyl index which was called Chemical Aging Index (CAI), the aging index was calculated by using Equation 6:

$$
C A I=\frac{\text { Aged Carbonyl index }- \text { Unaged Carbonyl index }}{\text { Unaged Carbonyl index }}
$$

Figure 9 shows the aging index for PG 64-22, NCmodified and BNC-modified binders. The aging index for BNC is significantly lower than that of the two other binders. This reduction in aging rate can be related to increasing interlayer spacing and consequently better dispersion of nanoclay and acting as an oxygen barrier. In the other hand a previous study showed that bio-binder has an effect on reducing the aging susceptibility of asphalt binder (Fini et al., 2017). This effect can be involved in reducing aging susceptibility due to presence of bio-binder molecules on the surface of nanoclay and reacting with asphalt molecules. While the application of bio-binder as an organic modifier helps improve the distribution of nanoclay by increasing the d-spacing of silica nano-platelets to improve the rheological performance of asphalt binder in high and intermediate temperature, it appears that biobinder also has a delaying effect of oxidation due to the relatively low affinity of bio-binder molecules for interaction with oxygen (Lamontagne et al., 2001). The relatively lower polarizability of bio-binder molecules which was shown elsewhere (Mousavi et al., 2016b), is well in-line with observations in this study showing BNCmodified binder has higher resistance to oxidation than both neat binder and NC modified binder.

\section{Conclusion}

This paper investigates the effectiveness of treating asphalt binder with nanoclay modified with an amide-enriched bio-binder to reduce the binder's aging susceptibility. Accordingly, a comparative study was conducted to examine physiochemical properties of asphalt before and after the addition of pure and treated clay. Treatment was done using a bio-modifier made from thermochemical conversion of swine manure. The paper mainly examines the effect of an amide-enriched compound on the intercalation of montmorillonite clay. Bio-modified nanoclay samples with three ratios were prepared and the extent of their intercalation was studied using XRD and FTIR analysis. The results showed a notable increase in clay interlayer spacing, which was attributed to the interactions of amide functional groups of bio-binder with the silicate layer of MMT. A possible mechanism for interaction of amide molecules with silicate layer of nanoclay was assumed to be through hydrogen bonding between a nitrogen of amide and an oxygen of $-\mathrm{Si}-\mathrm{O}$ in the interlayer of nanoclay, which in turn promotes the introduction of long-tail organic molecules inside the layers and consequently increases the interlayer spacing of nanoclay.

The results further showed that the 50-50 concentration of bio-binder and clay led to the highest increase in gallery spacing. Therefore, aforementioned modified clay was further introduced in $2 \%$ by the weight of asphalt binder to study its effect on asphalt oxidation resistance.

The rheological and chemical characterizations were done to evaluate the aging susceptibility of asphalt binder after modification with amide enriched biomodified nanoclay. The results showed that introduction of bio-modifier to the interlayer of nanoclay has enhanced d-spacing of the clay layers and consequently has led to the better distribution of nanoclay particles through the asphalt matrix. This distribution is the result of intercalation and exfoliation of the clay layers which perform as an oxygen barrier inside the asphalt matrix. All the samples were exposed to the long and short term aging and viscosity aging index, rheological aging index based on the DSR and BBR results and also chemical aging index according to the FTIR results were calculated. All the results showed a significant reduction in the aging rate of modified asphalt binder with bio modified-nanoclay. Even though, untreated nanoclay had an effect in the reduction of aging rate but this improvement in aging susceptibility was more notably in bio modified-nanoclay.

\section{Acknowledgement}

This research is sponsored by the National Science Foundation (awards \#1546921 and \#1150695) and the University Transportation Center: Center for Highway Pavement Preservation. The contents of this paper reflect the view of the authors, who are responsible for the facts and the accuracy of the data presented. This paper does not constitute a standard, specification, or regulation. The authors would like to acknowledge the invaluable assistance provided by Daniel Oldham, Taylor Hawkins, Acacia Hines, Yaya Abou Salami and Daniel Folley of North Carolina A\&T State University.

\section{Author's Contributions}

Shahrzad Hosseinnezhad: Performed laboratory experiments and conducted data analysis of the research.

Elham H. Fini and Taher M. Abu-Lebdeh: Provided the research topic and guided the research development, experimental plan and data analysis. 


\section{Ethics}

No part of this article may be reproduced without written permission from the publisher or authors.

\section{References}

Amirkhanian, A.N., F. Xiao and S.N. Amirkanian, 2010. Evaluation of high temperature rheological characteristics of asphalt binder with carbon nano particles. J. Test. Evaluat., 39: 583-591.

DOI: 10.1520/JTE103133

Du, Z., Y. Li, X. Wang, Y. Wan and Q. Chen et al., 2011. Microwave-assisted pyrolysis of microalgae for biofuel production. Bioresour. Technol., 102: 4890-4896. DOI: 10.1016/j.biortech.2011.01.055

El-Shafie, M., I.M. Ibrahim and A.M.M. Abd El Rahman, 2012. The addition effects of macro and nano clay on the performance of asphalt binder. Egypt. J. Petrol., 21: 149-154.

DOI: 10.1016/j.ejpe.2012.11.008

Fini, E.H., I.L. Al-Qadi, Z. You, B. Zada and J. MillsBeale, 2012. Partial replacement of asphalt binder with bio-binder: Characterisation and modification. Int. J. Pavement Eng., 13: 515-522. DOI: $10.1080 / 10298436.2011 .596937$

Fini, E.H., E.W. Kalberer, G. Shahbazi, M. Basti and Z. You et al., 2010. Chemical characterization of biobinder from swine manure: Sustainable modifier for asphalt binder. J. Mater. Civil Eng., 23: 1506-1513. DOI: 10.1061/(ASCE)MT.1943-5533.0000237

Fini, E.H., S. Hosseinnezhad, D.J. Oldham, C. Chailleux and V. Gaudefroy, 2017. Source dependency of rheological and surface characteristics of biomodified asphalts. Road Mater. Pavement Design, 18: $408-422$. DOI: $10.1080 / 14680629.2016 .1163281$

Garcia-Lopez, D., I. Gobernado-Mitre, J.F. Fernandez, J.C. Merino and J.M. Pastor, 2005. Influence of clay modification process in PA6-layered silicate nanocomposite properties. Polymer, 46: 2758-2765. DOI: $10.1016 /$ j.polymer.2005.01.038

Goh, S.W., M. Akin, Z. You and X. Shi, 2011. Effect of deicing solutions on the tensile strength of micro- or nano-modified asphalt mixture. Constr. Build. Mater., 25: 195-200.

DOI: 10.1016/j.conbuildmat.2010.06.038

Gupta, R.K., V. Pasanovic-Zujo and S.N. Bhattacharya, 2005. Shear and extensional rheology of EVA/layered silicate-nanocomposites. J. NonNewton Fluid, 128: 116-125.

DOI: $10.1016 /$ j.jnnfm.2005.05.002

Hrachova, J., J.P. Komadela and V.S. Fajnorb, 2007. The effect of mechanical treatment on the structure of montmorillonite. Mater. Lett., 61: 3361-3365. DOI: 10.1016/j.matlet.2006.11.063
Hosseinnezhad, S., E.H. Fini, B.K. Sharma, M. Basti and B. Kunwar, 2015. Physiochemical characterization of synthetic bio-oils produced from bio-mass: A sustainable source for construction bio-adhesives. RSC Adv., 5: 75519-75527. DOI: 10.1039/C5RA10267G

Jahromi, S.G. and A. Khodaii, 2009. Effects of nanoclay on rheological properties of bitumen binder. Constr. Build. Mater., 23: 2894-2904.

DOI: $10.1016 /$ j.conbuildmat.2009.02.027

Karllsson, R., U. Isacsson and J. Ekblad, 2006. Rheological characterisation of bitumen diffusion. J. Mater. Sci., 42: 101-108. DOI: $10.1007 / \mathrm{s} 10853-006-1047-y$

Lamontagne, J., F. Durrieu, J. Planche, V. Mouillet and J. Kister, 2001. Direct and continuous methodological approach to study the ageing of fossil organic material by infrared microspectrometry imaging: Application to polymer modified bitumen. Analytica Chimica Acta, 444: 241-250. DOI: 10.1016/S0003-2670(01)01235-1

Liu, G., S. Wu, M. Van de ven, A. Molenaar and J. Besamusca, 2010. Characterization of organic surfactant on montmorillonite nanoclay to be used in bitumen. J. Mater. Civil Eng., 22: 794-799.

DOI: 10.1061/(ASCE)MT.1943-5533.0000013

Lee, L.J., C. Zeng, X. Cao, X. Han and J. Shen et al., 2005. Polymer nanocomposite foams. Comp. Sci. Technol., 65: 2344-2363. DOI: 10.1016/j.compscitech.2005.06.016

Maiti, P. and M. Okamoto, 2003. Crystallization controlled by silicate surfaces in nylon 6-clay nanocomposites. Macromolecular Mater. Eng., 288: 440-445. DOI: 10.1002/mame. 200390040

Mousavi, M., F. Pahlavan, D. Oldham, T. Abdollahi and E.H. Fini, 2016a. Alteration of intermolecular interactions between units of asphaltene dimers exposed to an amide-enriched modifier. RSC Adv., 6: 53477-53492. DOI: 10.1039/C6RA07506A

Mousavi, M., F. Pahlavan, D. Oldham, S. Hosseinnezhad and E.H. Fini, 2016b. Multiscale investigation of oxidative aging in biomodified asphalt binder. J. Phys. Chem. C, 120: 17224-17233.

DOI: 10.1021/acs.jpcc.6b05004

Ramos Filho, F.G., T.J.A. Melo, M.S. Rabello and S.M.L. Silva, 2005. Thermal stability of nanocomposites based on polypropylene and bentonite. Polym. Degrad. Stabil., 89: 383-392. DOI: $10.1016 /$ j.polymdegradstab.2004.12.011

Rubio, M.C., G. Martinez, L. Baena and F. Moreno, 2012. Warm mix asphalt: An overview. J. Cleaner Product., 24: 76-84. DOI: 10.1016/j.jclepro.2011.11.053

Su, X.F., G. Zhang, K., Xu, J.H. Wang and C.L. Song et al., 2008. The effect of MMT/modified MMT on the structure and performance of the superabsorbent composite. Polym. Bull., 60: 69-78. DOI: $10.1007 / \mathrm{s} 00289-007-0843-0$ 
Touchaleaume, F., J. Soulestin, M. Sclavons, J. Devaux and F. Cordenier et al., 2011. Efficient one-step melt-compounding of copolyetheramide/pristine clay nanocomposites using water-injection as intercalating/exfoliating aid. eXPRESS Polymer Lett., 5: 1085-1101.

DOI: 10.3144/expresspolymlett.2011.106

Williams, R.C., J. Peralta and K.L.N. Puga, 2015. Development of non-petroleum-based binders for use in flexible pavements-Phase II. Iowa State University.

Yao, H., Z. You, L. Li, S.W. Goh and C.H. Lee et al., 2013. Rheological properties and chemical analysis of nanoclay and carbon microfiber modified asphalt with Fourier transform infrared spectroscopy. Constr. Build. Mater., 38: 327-337. DOI: 10.1016/j.conbuildmat.2012.08.004

Yao, H., Q. Dai and Z. You, 2015. Fourier Transform Infrared Spectroscopy characterization of agingrelated properties of original and nano-modified asphalt binders. Constr. Build. Mater., 101: 10781087. DOI: $10.1016 /$ j.conbuildmat.2015.10.085

Yang, X., Z. You and Q. Dai, 2013. Performance evaluation of asphalt binder modified by bio-oil generated from waste wood resources. Int. J. Pavement Res. Technol., 6: 431-439. DOI: 10.6135/ijprt.org.tw/2013.6(4).431

Yariv, S and H. Cross, 2002. Organo-clay Complexes and Interactions. 1st Edn., CRC Press, New York, ISBN-10: 0824705866, pp: 688.
You, Z., J. Mills-Beale, J.M. Foley, S. Roy and G.M. Odegard et al., 2011. Nanoclay-modified asphalt materials: Preparation and characterization. Constr. Build. Mater., 25: 1072-1078.

DOI: 10.1016/j.conbuildmat.2010.06.070

Zhang. H.L., J.Y. Yu, L.H. Xue and Z.C. LI, 2011. Effect of montmorillonite organic modification on microstructures and ultraviolet aging properties of bitumen. J. Microscopy, 244: 85-92. DOI: $10.1111 /$ j.1365-2818.2011.03511.x

Zhang, H., J. Yu and S. Wu, 2012. Effect of montmorillonite organic modification on ultraviolet aging properties of SBS modified bitumen. Constr. Build. Mater., 27: 553-559.

DOI: $10.1016 /$ j.conbuildmat.2011.07.008

Zulfiqar, S., Z. Ahmad and M.I. Sarwar, 2008. Preparation and properties of aramid/layered silicate nanocomposites by solution intercalation technique. Poly. Adv. Technol., 19: 1720-1728.

DOI: $10.1002 /$ pat. 1186 